supervision of a surgeon. This warning seems necessary in view of the fact that it is one of the publications of the St. John Ambulance Association. Medical students can have no better or sounder guide to take them through the first years of their surgical training, and a testimony of this is the issue of this twelfth edition. It is a pity that opportunity has not been taken to rewrite the chapter on the treatment of drowning, for although it is stated that Scbäfer's method of artificial respiration is to be preferred in these cases and the method is described, the whole treatment of drowning is dealt with as if Silvester's method (which is figured) were still recommended to be used.

Stanford's Indexed Atlas of the County of London, with Parts of the Adjaoent Boroughs and Urban Districts. With a Preface by Sir LAurence GoMme. London: Edward Stanford. 1911. Pp. 159. Price, cloth, 7s. 6d. net; leather, 10s. $6 d$. net.-This sectional atlas consists of 84 maps, with an index map, a contour chart of altitudes, and a chart of the surface geology of the area covered by the maps. There is also an index to streets, squares, roads, terraces, places, lanes, railway stations, hospitals, L.C.C. fire-stations, the chief public buildings, \&c., that fall within the limits of the map. It contains upwards of 12,000 names and fills 159 pages. We note the insertion of only one Midmoor-road, that in Wandsworth. Is there not one also in Wimbledon? This is the only slip, if it is one, that we have noted. The boundaries of the metropolitan boroughs and of the adjacent municipal boroughs, urban districts, and rural districts are marked in red ; parks and open spaces are coloured green; water, blue; and roads along which tramways run, yellow. By a pale brown tint, continuous or broken, on either side of the streets it is shown whether the houses are terraced or detached, a useful piece of information to houseseekers. The preface contains much interesting and useful information. The work well sustains the reputation of the publisher as a cartographer, and can be highly commended.

The Social Guide, 1911. Edited by Mrs. HugH ADAMS and EDITH A. BRowne. London: Adam and Charles Black. Pp. 252. Price 2s. 6d. - This is a useful book of reference to the social functions of the year, and should be especially appreciated by visitors to this country from other lands. The events of the year, with all necessary details, are arranged in alphabetical order and also accordirg to the calendar. Several pages are devoted to the Coronation. The only seeming inaccuracy that we have found in the book is one for which we willingly pardon the compilers, who state that it is oustomary for ladies in all parts of every London theatre to semove their hats. The italics are ours; the optimism as to manners, the author's.

Medico-Psychological Association of Great BRITAIN AND IRELAND.-The next general or quarterly meeting of the association will be held at 11, Chandos-street, Carendish-square, London, W., on Tuesday, May 23rd, under the presidency of Dr. John Macpherson, at 3 o'clock. Papers will be read on the Treatment of Puerperal Insanity with Antistreptococcic Serum by Dr. Nathan Raw, and on Pathological and Prolonged Sleep by Dr. Maurice Eden Paul, subsequent to which a cinematograph demonstration of some scientific films of general medical interest will be given. Members will afterwards dine together at the Café Monico Restaurant at 7 P.M. (Cost of dinner $7 s$. 6 2 , exclusive of wine. Evening dress optional.) Dr. C. Hubert Bond, the honorary general secretary, announces that he will be much assisted in arranging the programme for the annual meeting if members desiring to read papers thereat will kindly communicate with him as soon as possible at 11, Chandos-street, Cavendish-square, London, W.

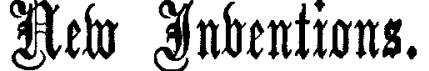

\section{AN IMPROVED STETHOSCOPE.}

Messrs. Allen and Hanburys of Wigmore-street, London, W., have made for me the stethoscope shown in the accompanying illustration. The improvements claimed are that it is mathematically and physically correct throughout. The combined sectional areas of the two smaller tubes are

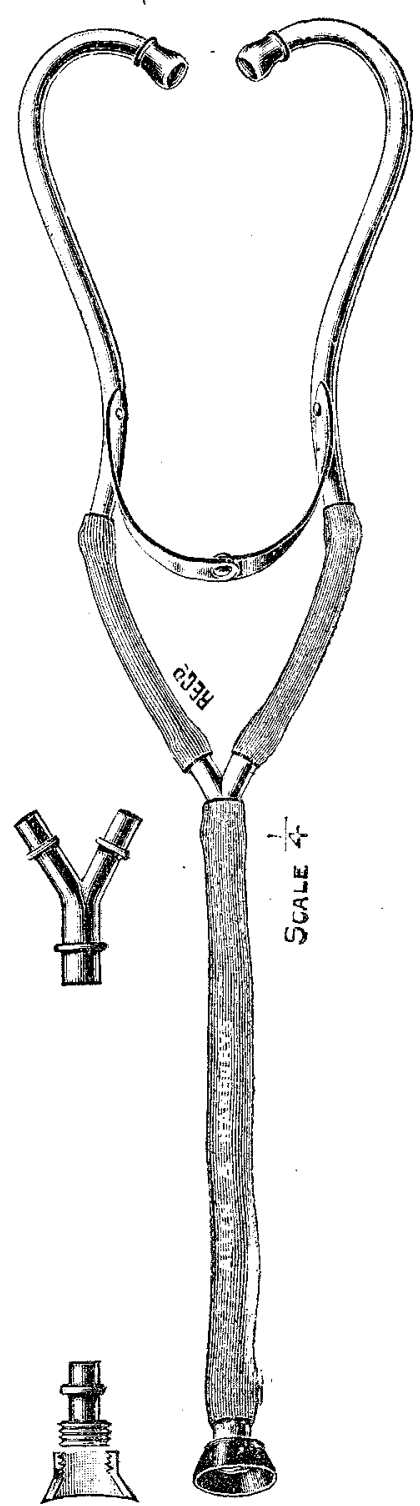
equal to the sectional area of the larger tube. There is no widening or narrowing of the lumen of the tube from chestpiece to ear, and therefore nothing to interfere with the sound waves. This is achieved by the following methods. The worm on the chest-piece is external; the diameter of the rubker tube is the same as that of the proximal end of the chest-piece; the latter has a knife edge, so that the constriction which ordinarily occurs immediately beyond the attachment of a rubber tube to a rigid tube does not take place; the three orifices of the "Y" tube bave also knife edges. There is no lessening of the calibre at the junction of the tube and ear-piece. The opening of the latter is slightly larger than that of the tube, so that when placed in the ear there is no choking. The advantages of the instrument are that all exaggeration of the sound, and also any accentuation of a com. ponent of the sound beyond another are avoided, and the exact sound produced is conveyed to the ear. Moreover, adventitious sounds are excluded with great ease. This is particularly noticeable in listening to the breath sounds. The convenience of the single tube is very great. If the test recommended by Hutchison and Rainy in their "Olinical "Methods" be applied, it will be found that the intensity of the sound-the ticking of a watch-is at least double that of an ordinary binaural instrument. I have to express my indebtedness to Mr. Lewis, of Messrs. Allen and Hanburys, for his courtesy and his interest in the designing and completing of the instrument.

Oxshott,'Surrey. - T. C. BLACKWELL, M.D. Edin.

\section{THE PURIS SYPHON.}

THE complete exclusion of metallic fittings from the head of the familiar soda syphon is, of course, a distinct hygienic gain. The head of the "Puris" syphon is made entirely of porcelain, and the way in which it acts, both to seal and to deliver the water, is ingenionsly simple. There are no levers or springs, the water being delivered simply by pressing a knob which is not unlike in size and shape an electric bell push. The valve is an ingenious device consisting of a rolling ring which covers and uncovers the ports of the valve, acting automatically with the assistance of the back pressure within the syphon; and the great simplicity of the syphon head, which is practically in two parts, is a material feature of the invention, enabling the syphon to be taken to pieces in a few seconds and re-fitted complete within half a minute, so that the syphons can be thoroughly washed out when requi ed. A specimen of this syphon head was submitted to us by Messrs. Rayner and Co., of 37, Chancery-lane, London, W.O. 